\title{
EDITORIAL
}

\section{Neonatal and infant death: what bereaved parents can teach us}

Journal of Perinatology (2007) 27, 467-468; doi:10.1038/sj.jp.7211777

\author{
All happy families resemble one another, \\ Each unhappy family is unhappy in its own way. \\ Leo Tolstoy, from \\ Anna Karenina
}

While neonatal and perinatal practices have advanced over the past four decades, death remains altogether too familiar a possibility, or event, to professional caregivers in the perinatal setting. High-risk obstetrical services that now include prenatal[fetal] diagnostic and interventional clinics, and tertiary neonatal intensive care units (NICUs) are populated with patients who face incredible odds for experiencing perinatal loss as a miscarriage, stillbirth or neonatal death, or to experience the loss of an NICU graduate before the first birthday. What is intended to be helpful and supportive information, applied science and technology, and collaborative care with parents for their fetus or newborn may be variably received by parents, interpreted in meaning and intent, and perceived as beneficial, satisfactory, or neither, when faced with fetal/neonatal death as the outcome.

From about 1980 forward, the literature in perinatal loss is rich with the perspectives of psychologists, social workers, nurses, bereaved parents and occasional physicians. It entails empirical studies, numerous case reports and series, qualitative interviews, major textbooks and, recently, online resources. Review articles, present in psychological, medical and nursing literature, have repeatedly summarized a number of key findings for clinicians. ${ }^{1-3}$ Perspectives from couples, fathers, low-income African Americans and from those experiencing recurrent perinatal loss have all been reported. ${ }^{1-5}$ Yet only in 2007 has a systematic review of reported bereaved parents' experiences been published in the United States. ${ }^{6}$ What do we know? What is new? Have we made improvements in caring for newborns who are dying? What can bereaved parents teach us?

In this issue of the Journal, Brosig et al. ${ }^{7}$ report on parental interviews following neonatal or infant death and relate facts that must be interpreted not only in light of the history and progress of neonatology, or our collective experiences, but also in consideration of recent guidelines pertaining to palliative care. In 2000, the American Academy of Pediatrics published the statement entitled Palliative Care for Children, encouraging improvements in pediatrician and interdisciplinary staff education and service capacity, access to palliative care services, an integration of palliative and curative services, and encouraged research to direct improved care. ${ }^{8}$ The 2003 Institute of Medicine's report When
Children Die further elaborated on the many needs of patients, parents and hospital staff in attending to the interdisciplinary supportive care provided in the context of the dying infant and child. ${ }^{9}$ Now we are given insights into parental views in an age of increasing awareness to the potential benefits of providing comprehensive, interdisciplinary palliative care. The center from which Brosig's paper is published has employed a pediatric palliative care service for 10 years, and has expanded its role to include perinatal consultation (both in the NICU and also in the prenatal context). Brosig et al. ${ }^{7}$ reports on follow-up in 19 interviews, from of an original cohort of 67 families, addressing parental perspectives after experiencing neonatal or young infant death. While many of the findings reiterate those from other studies over the past 25 years, the added value of both parents contributing to the interview in more than half of the cases and the use of formal evaluative tools (Revised Grief Experience Inventory, Surrogate Hospital AFTERDEATH Interview and Post-Death Adaptation Scale) make this report noteworthy. Further, this work gives evidence for the change in the focus of grief work among the bereaved (including parents) that has occurred over recent years - moving away from confronting the reality of loss, so as to resolve the grief and be free of any 'bondage' the deceased may hold over them, or working through stages of acceptance and adjustment, toward a new realization of continuing bonds. ${ }^{1}$

It is this new perspective on grieving that the parents in Brosig's study affirm - that their children mattered; that they are remembered; that although deceased these children remain central to their parents' lives... in conversation, in photographs, in their homes and even in their social and religious activities. This point may be of import to hospital staff who are at times uncomfortable with the appropriateness of maintaining contact with the parents of a former patient. As Davies states, 'the concept of continuing bonds challenges the dominant assumption that resolution of grief is achieved through severing bonds with the deceased'. ${ }^{1}$ But from studies reported over the past 10 years, the desire for parents to maintain some contact with an extended 'pseudo-family' in the hospital is increasingly apparent, especially if the infant never left the hospital. The value of shared memories makes obvious the meaning of mementos, photographs, notes, cards, toys, clothes, blankets or other objects from the hospital that parents can take home when they cannot take home a child. Further, parents need to know that their children had an impact upon others - such as the professional caregivers who knew and worked with their child - and continue to do so. 
Bereaved parents, then, can teach many things that may improve the end-of-life, and everyday, care we render to our most vulnerable patients. These include, but are not limited to, the following:

1. Honesty matters. Parents value information that is current, relevant and compassionately conveyed; even if imparting it entails giving 'bad news'.

2. Decisions are not the sole purview of the physician. To decide requires information - not the least of which is an end, or goal, of care for which decisions are being considered. Parents can, and desire to, make decisions for their child with the input from the clinical team. This is true even, perhaps especially, when decisions to limit or withdraw life-support are being made.

3. The NICU is a community; in it, we need to take care of each other. In so doing, we provide a space in which thoughts, words and actions can provide comfort and care for parents and staff, as well as babies, when needed. While the physical space may enhance a good environment, that environment first is set by the tone, posture and sensitivity of the people present.

4. Language matters, be it good or bad. What is said cannot be taken back, and professionalism requires that self-interest be subsumed to patient-family interests, especially in such critical times and environments. Positive language, referring to a child by name, or providing reassurance or encouragement to parents is invaluable.

5. Presence is of utmost importance. Physicians, nurses, chaplains, social workers, child-life specialists and others can 'bear witness' through the process of perinatal loss, and parents value this.

6. The interdisciplinary clinical team contributes to parental coping. This is true when nurses support families at the bedside, physicians conduct autopsy reviews and conferences with parents, chaplains or community clergy assist with interpreting suffering and loss or assigning meaning, social workers aid parents in getting on with daily life and bereavement staff assist parents with bereavement support. In our respective disciplines and roles in the NICU, generally directed toward life-saving or life-extending care, we may not always be cognizant of how we help parents cope.

Mindfulness of our interrelational interdependence with others is of great import, especially in times of need. And as simple as it sounds, we need to be reminded - by parents as well as others - that mutual respect is of enduring value.

BS Carter

Division of Neonatology, Vanderbilt University Medical Center, Monroe Carell, Jr. Children's Hospital at Vanderbilt, Nashville,

TN, USA

\section{E-mail:Brian.Carter@Vanderbilt.edu}

\section{References}

1 Davies R. New understandings of parental grief: literature review. J Adv Nurs 2004; 46 506-513.

2 Badenhorst W, Hughes P. Psychological aspects of perinatal loss. Best Pract Res Clin Obstet Gynecol 2007; 21: 249-259.

3 Badenhorst W, Riches S, Turton p, Hughes P. Psychological aspects of stillbirth and neonatal death on fathers: systematic review. J Psychosom Obstet Gynaecol 2006; 27: 245-256.

4 Kavanaugh K. Perinatal loss in low-income African-American parents: the lived experience. J Obstet Gynecol Neonatal Nurs 2005; 34: 595-605.

5 Kavanaugh K, Robertson PA. Recurrent perinatal loss: a case study. Omega (Westport) 1999; 39: 133-147

6 Gold KJ. Navigating care after a baby dies: a systematic review of parent experiences with health providers. J Perinatol 2007; 27: 230-237.

7 Brosig CL, Pierucci R, Kupst MJ, Leuthner S. Infant end of life care: the parents perspective. J Perinatol 2007; 27: 510-516.

8 Committee on Bioethics and Committee on Hospital Care. Palliative care for children. Pediatrics 2000; 106: 351-357.

9 Committee on Palliative and End-of-Life Care for Children and Their Families, Board on Health Sciences Policy, Institute of Medicine. In: Field, MJ, Behrman, RE (eds). When Children Die: Improving Palliative and End-of-Life Care for Children and Their Families. National Academies Press: Washington, DC, 2003, p 3. 